\title{
Hydrotherapy Intervention for Patients Following Total Knee Arthroplasty: A Systematic Review
}

\section{Hydrotherapie-Interventionen für Patienten nach Knie- Totalendoprothesen: eine systematische Übersicht}

Authors

Youguang Zhuo ${ }^{1}$, Rongguo Yu1 ${ }^{1}$, Chunling $\mathrm{Wu}^{1}$, Yiyuan Zhang ${ }^{2}$

Affiliations

1 Department of Orthopedics, Fuzhou Second Hospital Affiliated to Xiamen University, Fuzhou, China

2 Department of Orthopedics, Fuzhou Second Hospital Affiliated to Xiamen University, Fuzhou Fujian, People's Republic of China, Fuzhou, China

Key words

Aquatic exercise, Hydrotherapy, Rehabilitation, Systematic review, Total knee arthroplasty

Schlüsselwörter

Wassergymnastik, Hydrotherapie, Rehabilitation, Systematische Übersichtsarbeit, Knietotalendoprothese (Knie-TEP)

received 23.09.2020

accepted 18.01.2021

online publiziert $\quad 26.02 .2021$

Bibliography

Phys Med Rehab Kuror 2021; 31: 170-176

DOI 10.1055/a-1368-6429

ISSN 0940-6689

(c) 2021. Thieme. All rights reserved.

Georg Thieme Verlag KG, Rüdigerstraße 14,

70469 Stuttgart, Germany

Correspondence

Dr. Yiyuan Zhang

Department of Orthopedics

Fuzhou Second Hospital Affiliated to Xiamen University

47 shangteng Road

People's Republic of China Fuzhou

350000 Fuzhou

Fujian

China

Tel.: 18450056048, Fax: 350000

zyy13905022511@163.com

Supplementary Material is available under https://doi. org/10.1055/a-1346-9402
ABSTRACT

Background Hydrotherapy or aquatic exercise has long been known as a source of postoperative rehabilitation proposed in routine clinical practice. However, the effect on clinical outcome as well as the optimal timing of hydrotherapy in patients undergoing total knee arthroplasty (TKA) remain unclear. The purpose of this review was to assess the influence of aquatic physiotherapy on clinical outcomes and evaluate the role of the timing of aquatic-therapy for clinical outcomes after undergoing TKA.

Methods An extensive literature search was performed in Embase, PubMed, and the Cochrane Library for randomized controlled trials (RCTs) that evaluated the impact of hydrotherapy on patients after TKA. The methodological quality of the trials was evaluated based on the Cochrane Risk of Bias Tool.

Results All available studies on postoperative hydrotherapy after TKA were included. The primary endpoint was to evaluate the effect of hydrotherapy on clinical outcomes. The secondary outcome was to explore the role of the timing of aquatic therapy for clinical outcomes following TKA.

Conclusion Although definitive conclusions could not be reached due to insufficient data, most studies indicated that participants benefited from aquatic-therapy in muscle strength, rather than gait speed, after TKA. Currently available data demonstrated that early postoperative hydrotherapy possessed a greater potential to improve clinical outcomes in main clinical scores and quality-adjusted life years (QALYs).

\section{ZUSAMMENFASSUNG}

Hintergrund Hydrotherapie oder Wassergymnastik ist seit langem als Therapieoption in der postoperativen Rehabilitation bekannt und ist Teil der klinischen Routinepraxis. Die Auswirkung auf das klinische Ergebnis sowie der optimale Zeitpunkt für eine Hydrotherapie bei Patienten nach einer Knietotalendoprothese (Knie-TEP) sind jedoch noch unklar. Ziel dieser Übersichtsarbeit war es, den Einfluss von Physiotherapie im Wasser auf das klinische Ergebnis sowie die Rolle des Zeitpunkts einer Wassertherapie für das klinische Ergebnis nach einer KnieTEP zu bewerten.

Methoden Es wurde eine umfangreiche Literatursuche in Embase, PubMed und der Cochrane Library nach randomisierten 
kontrollierten Studien (RCTs) durchgeführt, die den Einfluss von Hydrotherapie auf Patienten nach Knie-TEP evaluierten. Die methodische Qualität der Studien wurde anhand des Cochrane Risk of Bias Tools bewertet.

Ergebnisse Alle verfügbaren Studien zur postoperativen Hydrotherapie nach Knie-TEP wurden eingeschlossen. Der primäre Endpunkt war die Bewertung der Wirkung einer Hydrotherapie auf das klinische Ergebnis. Der sekundäre Endpunkt war die Untersuchung der Rolle des Zeitpunkts einer Wassertherapie für die klinischen Ergebnisse nach Knie-TEP.
Schlussfolgerung Obwohl aufgrund der unzureichenden Datenlage keine endgültigen Schlussfolgerungen gezogen werden konnten, deuteten die meisten Studien darauf hin, dass die Teilnehmer nach Knie-TEP von der Aquatherapie eher in Bezug auf die Muskelkraft als auf die Ganggeschwindigkeit profitierten. Die derzeit verfügbaren Daten zeigten, dass eine frühe postoperative Hydrotherapie eher eine Verbesserung der klinischen Ergebnisse in den wichtigsten klinischen Scores und qualitätskorrigierten Lebensjahren (QALYs) bewirken konnte.

\section{Introduction}

Osteoarthritis (OA) is the main cause of disability in older patients. An observational study based on the Chinese population estimated that the prevalence of symptomatic knee OA was nearly $8.1 \%$ [1]. Additionally, an analysis based on health insurance claims indicated that the prevalence of knee OA was $12.1 \%$ in Germany, in which females were more often affected than males (13.4 vs. 9.7\%) [2]. Across Europe, age-standardized, self-reported, and doctor diagnosed OA ranged from $2.8 \%$ in Romania to $18.3 \%$ in Hungary [3]. Symptomatic knee OA is highly prevalent among people aged over 50 years, affecting more than 250 million people worldwide [4]. The incidence of knee $\mathrm{OA}$ is increasing rapidly as the elderly population grows. As a result, an increasing burden is imposed on the healthcare system.

Total knee replacement is an effective treatment for end-stage knee OA, aiming to relieve pain and improve joint function. The number of TKAs has increased significantly over the past few decades, and future demand is expected to rise rapidly [5, 6]. However, there is a notable lack of consensus on postsurgical treatment $[7,8]$. After TKA, an intensive rehabilitation program is typically performed focusing on stretching, muscle strengthening, range of motion recovery, neuromuscular function, gait rehabilitation, and proprioceptive recovery. It has been emphasized that the evaluation of rehabilitation of the patient following TKA should be a priority [9].

Aquatic physiotherapy, which is a low-impact sport, has long been known as a source of postoperative rehabilitation. Due to the intrinsic properties of water, such as natural buoyancy, hydrostatic pressure, thermodynamics, hydrodynamics and viscosity, hydrotherapy can provide suitable exercise options for balance, muscle strengthening and gait training for patients who have undergone TKA. The aforementioned properties of water cannot be easily replaced by any other tool [10]. First of all, swelling in the lower extremities can be reduced by hydrostatic forces from immersion combined with exercise [11]. Secondly, immersion in water can relieve body-weight and allows patients to move their legs more easily, resulting in patients having a pleasurable experience when exercising in water [12]. Moreover, by varying the speed of movement in the water, different resistances can be obtained, which are beneficial in developing increased muscular strength [13]. Muscle coordination is also enhanced, owing to the sustained balance required for pool exercise [14]. Finally, when in thermo-neutral water, changes in the autonomic and circulatory systems increase blood flow to muscles and tissues to facilitate healing, and sensory interpretations of pain are also regulated [15]. When the temperature is set at $34^{\circ} \mathrm{C}$, a positive impact is imposed on the relaxation of muscles and joint protection [16]. However, it is unclear whether a specific aquatic exercise program provides additional benefits following TKA compared to land-based therapy. Furthermore, there is frequent disagreement between therapists regarding the best timing for starting hydrotherapy.

The primary aim of this systematic review is to assess the influence of aquatic physiotherapy on clinical outcomes after TKA. The secondary purpose of this study is to evaluate the role of the timing of aquatic-therapy for clinical outcomes after TKA.

\section{Methods}

The present systematic review was performed according to the PRISMA guidelines [17] and followed the Cochrane methodology for systematic reviews [18].

\section{Search strategy}

Embase, PubMed and the Cochrane Library were searched by 2 of the authors. Prospective randomized trials were searched using combinations of the following terms: hydrotherapy, aquatic physiotherapy, water-based exercise, aquatic therapy, pool therapy, balneotherapy, aquatic training, total knee arthroplasty, TKA, total knee replacement, and TKR.

First, studies retrieved were screened according to their title and abstract. Following first selection and exclusion of nonrelevant papers, 2 authors retrieved the full text of potentially eligible articles for inclusion. Disagreements were resolved via discussions with the third author. After the electronic search was completed, the bibliography of the searched articles were carefully reviewed to identify further studies for inclusion. The specific process of including studies is shown in $>$ Figure 1.

\section{Inclusion and exclusion criteria}

All RCTs comparing the clinical efficacy between hydrotherapy with land-based exercise or nothing undergoing primary TKA were taken into consideration in the present study. Studies comparing the results of different hydrotherapy timings were also included. Exclusion criteria included non-RCTs, studies involving revision knee arthroplasty, bilateral TKA and other surgical approaches, such as total hip arthroplasty. 


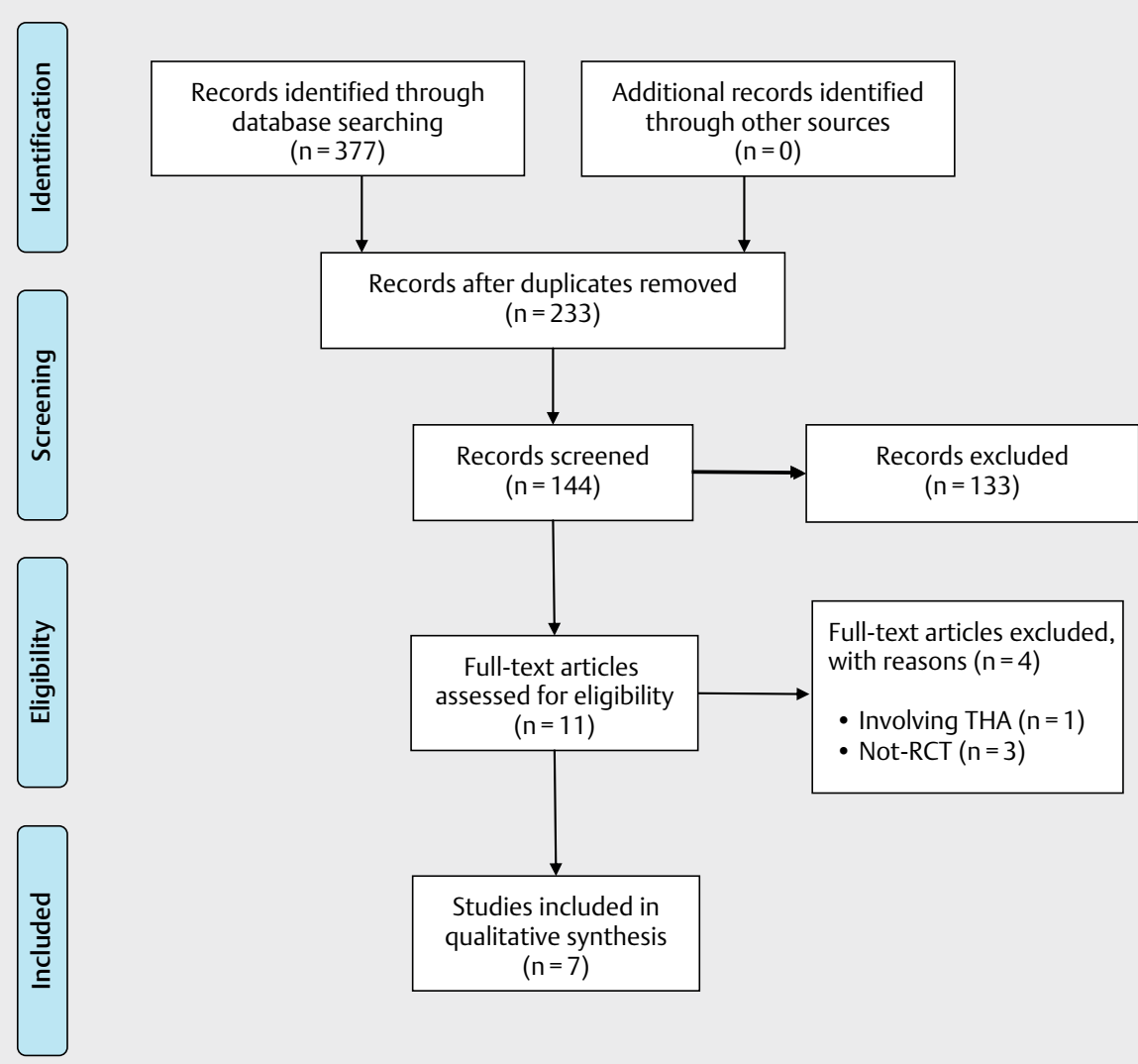

-Fig. 1 The flow diagram detailing our literature search.

\section{Data collection and analysis}

Data were extracted from the included articles based on the clinical outcomes considered for the purpose of this review. Generic data concerning the paper taken after extraction are outlined in

- Table 1.

\section{Risk of bias assessment}

The Cochrane risk of bias assessment tool was applied, which provides a grade of risk of bias for the index study in 7 elements of the study design (random sequence generation, allocation concealment, blinding, selective reporting, incomplete outcome data, and other bias).

\section{Results}

\section{Results of the search}

A total of 377 related studies were initially identified via database searches. Accordingly, 144 duplicates were excluded by Endnote $\mathrm{X} 8$, and 133 studies were removed based on the title and abstract. Additionally, 4 further papers were excluded for not being RCTs and involving THA. Finally, 7 papers were included in the study ( $\vee$ Figure 1).

The results of risk of the bias assessment are presented in > Table 2.
The sample size of the included studies ranged from 20 to 185 , and the range of the average age of the diverse studies was 58.5 to 70.9 years.

\section{Hydrotherapy vs. land-based physiotherapy or no intervention}

Compared to land-based physiotherapy, 2 studies found that hydrotherapy improved stair climbing power (SCP) [9], knee edema [9], hip abductor strength [19], and quadriceps strength [19]. However, it had no additional advantages in the 6-Minute Walk test (6MWT) [9] and 10-m walk test [19]. Compared to no intervention, two studies $[20,21]$ conducted by the same authors found no difference in maximal walking speed, while a significant improvement was found in habitual walking speed, knee extension and flexion power, stair ascending time, and the sit-to-stand test and muscle cross-sectional area (CSA) at 3 months of follow up. However, these advantages, except for knee extension and flexion power, disappeared at 12 months of follow up.

The Western Ontario and McMaster Universities Osteoarthritis Index (WOMAC) was mentioned in 4 papers [9, 20-22]. Of these, one study reported a significant improvement in the three subscales (function, pain, and stiffness) compared to land-based physiotherapy [22]. In contrast, three other studies reported no differences in the three subscales with the exception of one article that reported significant improvements in WOMAC function [9]. 
- Table 1 Characteristics of included studies.

\begin{tabular}{|c|c|c|c|c|c|c|c|}
\hline Study & $\begin{array}{l}\text { Number } \\
\text { of } \\
\text { patients }\end{array}$ & Mean age $(y)$ & Intervention & Comparison & Dosage & Outcome & $\begin{array}{l}\text { Follow- } \\
\text { up }\end{array}$ \\
\hline $\begin{array}{l}\text { Giaquinto } \\
\text { et al. } 2010 \\
\text { [19] }\end{array}$ & 58 & $\begin{array}{l}\text { Groups } \\
\text { matched by } \\
\text { age, gender, } \\
\text { and body mass } \\
\text { index (BMI) }\end{array}$ & hydrotherapy & $\begin{array}{l}\text { Conventional gym } \\
\text { treatment }\end{array}$ & $\begin{array}{l}40 \text { min, } \\
6 \text { days/w, 3w }\end{array}$ & WOMAC & $6 \mathrm{mo}$ \\
\hline $\begin{array}{l}\text { Harmer } \\
\text { et al. } 2009 \\
{[6]}\end{array}$ & 102 & $\begin{array}{l}\text { Water-based } \\
\text { group: } 68.7 \\
\text { Land-based } \\
\text { group: } 67.8\end{array}$ & $\begin{array}{l}\text { Water-based } \\
\text { treatment }\end{array}$ & $\begin{array}{l}\text { Conventional gym } \\
\text { treatment }\end{array}$ & $\begin{array}{l}60 \text { min, } \\
2 \text { days/w, } 6 \mathrm{w}\end{array}$ & $\begin{array}{l}\text { WOMAC, } \\
\text { 6-MWT, SCP, } \\
\text { knee edema }\end{array}$ & $8 w$ to $26 w$ \\
\hline $\begin{array}{l}\text { Liebs } \\
\text { et al. } 2012 \\
\text { [20] }\end{array}$ & 185 & $\begin{array}{l}\text { Group A: } 68.5 \\
\text { Group B } 70.9\end{array}$ & $\begin{array}{l}\text { Aquatic exercise } \\
\text { commenced D6 }\end{array}$ & $\begin{array}{l}\text { Aquatic exercise } \\
\text { commenced D14 }\end{array}$ & $\begin{array}{l}30 \text { min, } \\
3 \text { days/w, } 5 w\end{array}$ & $\begin{array}{l}\text { WOMAC, LKS, } \\
\text { SF-36 }\end{array}$ & $\begin{array}{l}3 \mathrm{mo} 6 \mathrm{mo} \\
12 \mathrm{mo} \\
2 \mathrm{yrs}\end{array}$ \\
\hline $\begin{array}{l}\text { Liebs } \\
\text { et al. } 2016 \\
\text { [21] }\end{array}$ & 185 & $\begin{array}{l}\text { Group A: } 68.5 \\
\text { Group B } 70.9\end{array}$ & $\begin{array}{l}\text { Aquatic exercise } \\
\text { commenced D6 }\end{array}$ & $\begin{array}{l}\text { Aquatic exercise } \\
\text { commenced D14 }\end{array}$ & $\begin{array}{l}30 \text { min } \\
3 \text { days/w, } 5 \mathrm{w}\end{array}$ & QALY & $\begin{array}{l}3 \mathrm{mo} 6 \mathrm{mo} \\
12 \mathrm{mo} \\
2 \mathrm{yrs}\end{array}$ \\
\hline $\begin{array}{l}\text { Rahmann } \\
\text { et al. } 2009 \\
{[16]}\end{array}$ & 20 & $\begin{array}{l}\text { Group 1: } 70.4 \\
\text { Group 2: } 69.4\end{array}$ & $\begin{array}{l}\text { Group 2: aquatic } \\
\text { physiotherapy } \\
\text { program ( } 30 \% \text { body } \\
\text { weight) }\end{array}$ & $\begin{array}{l}\text { Group 1: ward physio- } \\
\text { therapy treatment } \\
\text { each day, following } \\
\text { the standard } \\
\text { orthopedic clinical } \\
\text { pathway }\end{array}$ & $\begin{array}{l}40 \text { min daily } \\
\text { D4 until } \\
\text { discharge }\end{array}$ & $\begin{array}{l}\text { WOMAC, } \\
\text { 10MWT, hip } \\
\text { abductor } \\
\text { strength, } \\
\text { quadriceps } \\
\text { strength }\end{array}$ & $\begin{array}{l}\mathrm{D} 143 \mathrm{mo} \\
6 \mathrm{mo}\end{array}$ \\
\hline $\begin{array}{l}\text { Valtonen } \\
\text { et al. } 2010 \\
{[17]}\end{array}$ & 50 & $\begin{array}{l}\text { Training Group } \\
66.2 \text { Control } \\
\text { Group } 65.7\end{array}$ & $\begin{array}{l}\text { Training group: } \\
\text { 12-week progressive } \\
\text { aquatic resistance } \\
\text { training }\end{array}$ & No intervention & $\begin{array}{l}30 \text { to } 40 \mathrm{~min} \text {, } \\
2 \text { days/w, } \\
14 \mathrm{w}\end{array}$ & $\begin{array}{l}\text { WOMAC, HWS, } \\
\text { stair ascending, } \\
\text { KEFP, } \\
\text { sit-to-stand } \\
\text { test, muscle } \\
\text { CSA }\end{array}$ & $3 \mathrm{mo}$ \\
\hline $\begin{array}{l}\text { Valtonen } \\
\text { et al. } 2011 \\
{[18]}\end{array}$ & 42 & $\begin{array}{l}\text { Training Group } \\
65.8 \text { Control } \\
\text { Group } 66.4\end{array}$ & $\begin{array}{l}\text { Training group: } \\
\text { 12-week progressive } \\
\text { aquatic resistance } \\
\text { training }\end{array}$ & No intervention & $\begin{array}{l}30 \text { to } 40 \text { min, } \\
2 \text { days/w, } \\
14 w\end{array}$ & $\begin{array}{l}\text { KEFP, muscle } \\
\text { CSA, HWS, stair } \\
\text { ascending time, } \\
\text { sit-to-stand } \\
\text { test, WOMAC }\end{array}$ & $12 \mathrm{mo}$ \\
\hline
\end{tabular}

CSA: cross-sectional area, LKS: Lequesne Knee Score, HWS: habitual walking speed, KEPF: knee extensor and flexor Power, QALY: quality-adjusted life year, SCP: stair climbing power, SF-36: Short-Form-36, WOMAC: The Western Ontario and McMaster Universities Osteoarthritis Index, 6-MWT: 6-Minute Walk test, 10MWT: 10-m walk test.

\section{Early vs. late aquatic therapy}

Two studies [23,24] performed by the same author reported that early aquatic therapy could improve WOMAC, Lequesne Knee Score, SF-36 (Short-Form-36), and the additional QALYs attributed to early aquatic-therapy were 0.01 years after knee arthroplasty. However, it was not statistically significant.

\section{Discussion}

Starting hydrotherapy has been deemed safe in orthopedic surgery as early as day four without increased risk of wound infection as long as proper waterproof dressings are applied [25]. However, there is a lack of consensus on whether it can improve clinical outcomes. The purpose of this systematic review was to analyze current evidence on the role of aquatic-therapy in patients' clinical outcomes and give a recommended timing for hydrotherapy following total knee arthroplasty.

Compared to land-based physiotherapy, aquatic-therapy had a beneficial effect on clinical outcomes following TKA with improvements in stair climbing power, knee edema, hip abductor strength, and quadriceps strength, however, it had no effect on the 6-MWT and $10-\mathrm{m}$ walk test. The role of aquatic-therapy is to improve strength and control over the knee joint to achieve compensatory functional stability and improve sensorimotor control [26-28]. When practicing hydrotherapy, TKA participants maintained balance on their feet and appeared cautious and more concerned about their gait quality than fast moving. Both pain and necessity to control knee stability account for this walking strategy.

Compared to non-intervention, a significant improvement was noted in habitual walking speed, knee extension and flexion power, 
- Table 2 Cochrane Risk of Bias Assessment. Low risk (L), High risk (H), Unclear (U).

\begin{tabular}{|c|c|c|c|c|c|c|}
\hline Study & $\begin{array}{l}\text { Random sequence } \\
\text { generation }\end{array}$ & $\begin{array}{l}\text { Allocation } \\
\text { concealment }\end{array}$ & Blinding & $\begin{array}{l}\text { Selective } \\
\text { reporting }\end{array}$ & $\begin{array}{l}\text { Incomplete } \\
\text { outcome data }\end{array}$ & Other bias \\
\hline Giaquinto et al. 2010 [19] & $U$ & L & $u$ & $\mathrm{~L}$ & L & L \\
\hline Harmer et al. 2009 [6] & $\mathrm{L}$ & L & L & $\mathrm{L}$ & $\mathrm{L}$ & L \\
\hline Liebs et al. 2012 [20] & L & L & $\mathrm{H}$ & L & L & L \\
\hline Liebs et al. 2016 [21] & L & L & $\mathrm{H}$ & $\mathrm{L}$ & $\mathrm{L}$ & $\mathrm{L}$ \\
\hline Rahmann et al. 2009 [16] & L & L & $\mathrm{L}$ & $\mathrm{L}$ & $\mathrm{L}$ & $\mathrm{H}$ \\
\hline Valtonen et al. 2010 [17] & $U$ & L & $\mathrm{H}$ & L & L & L \\
\hline Valtonen et al. 2011 [18] & U & L & $\mathrm{H}$ & L & L & L \\
\hline
\end{tabular}

stair ascending time, and the sit-to-stand test and muscle CSA at 3 months of follow up. Interestingly, improved muscle CSA disappeared at 12 months of follow up [21]. In healthy older adults, muscle CSA is maintained [29] or decreased [30] during a 6-month detraining period, while being 12 months without physical training is too long to maintain the effectiveness of training for muscle CSA. Similarly, the training effect on mobility, including habitual walking speed, stair ascending time, and the sit-to-stand test also disappeared, however, knee extension and flexion power were further improved [21]. This seemed to contradict the further improvement of activities after stopping training $[9,19]$. One possible cause is that the interventions were commenced during the acute recovery phase ( $<2$ wk post-surgery) in both studies $[9,19]$, rather than 4 to 18 months after surgery [21]. Meanwhile, these findings were consistent with studies in patients suffering from fibromyalgia, where muscle strength was maintained after the detachment period but mobility was not $[31,32]$. Accordingly, the results may indicate that the daily activity demands of the participants were not sufficient in sustaining training-induced changes in mobility. Indirectly, these results emphasize that patients should begin rehabilitation immediately after operation and should be encouraged to engage in hydrotherapy as a regular part of the rehabilitation process. Unfortunately, over $50 \%$ of patients who undergo total joint replacement do not respect physical activity guidelines, suggesting that patient education should be improved greatly [33].

In general, hydrotherapy works effectively for muscle strength improvement, rather than gait speed. Early hydrotherapy should be encouraged as a habitual part of the rehabilitation process.

Controversy still exists on whether hydrotherapy could improve WOMAC, as only one study reported that hydrotherapy significantly improved WOMAC scores [22]. Nonetheless, in most studies $[9,20,21]$, training had no additional effect on the self-reported physical status of patients, which may be due to relatively healthy participants who found no difficulties with simpler tasks, such as sitting and lying in bed [20,21]. Training also had no additional effect on pain, which was expected because of the relatively small pain score at baseline $[9,20,21]$. Unlike other studies, participants performed high-frequency exercise 6 days a week [22]. It may also be possible that high-frequency exercise habits accounted for significant improvements in WOMAC scores.
Early aquatic therapy was found to be beneficial following TKA, with improvements in WOMAC, Lequesne Knee Score, and SF-36 [23]. Moreover, additional QALYs attributed to early aquatic-therapy were 0.01 years after knee arthroplasty [24]. Early hydrotherapy ( 6 days after surgery) showed similar beneficial effects when using NSAIDs [23]. Unlike THA, a significantly higher number of patients are unsatisfied after TKA [34], leaving room for additional interventions. Early aquatic-therapy, apart from procedure volu$\mathrm{me}$, is a rare factor that may be influenced by healthcare professionals and has a clinically significant effect on the health-related quality of life of patients following TKA [23]. Notably, recent studies have also highlighted the role of spa therapy in increasing stress resilience by modulating cortisol levels [35] and enhancing the quality of life [36]. Unfortunately, the results did not demonstrate any statistically significance. Consequently, high-quality studies with appropriate methodologies are necessary in order to draw these conclusions.

This review possesses several limitations. First, the heterogeneity of postoperative rehabilitation programs as well as the various outcome measures reported do not allow for pooling of results and a statistical analysis. Second, it is unclear whether hydrotherapy is relevant in terms of the durability of the prosthetic implant due to its lack of coverage in the included articles, though it has been reported that a moderate or active lifestyle does not affect implant survival $[37,38]$. In addition, no study reported on surgical techniques and surgical details. Several surgical approaches and different implants are available that can significantly affect patients' recovery. All papers were assessed using the Cochrane Risk of Bias Assessment, showing only some incongruity in blinding. However, this did not appear to compromise the quality and relevance of the results.

\section{Conclusion}

Regardless of the fact that the heterogeneity of postoperative rehabilitation protocols and various outcome measures did not produce definitive conclusions, most studies suggest that participants benefit from aquatic-therapy after undergoing TKA. Although currently available data illustrates that early postoperative hydrotherapy has a greater potential in improving clinical outcomes, there is a lack of robust evidence in supporting it. Since aquatic-therapy 
is a non-invasive and low-cost activity, it would be clinically worthwhile to recommend it to patients undergoing TKA.

\section{Declarations}

The first author is responsible for misconduct in the research and writing process. The original images, data (including computer database) records involved in the paper have been saved and shared in accordance with relevant regulations and can accept verification.

\section{Funding}

There is no funding for this article.

\section{Authors' contributions}

YGZ and YYZ performed study design. RGY, CLW participated in literature search. YGZ and RGY oversaw quality assessment. YGZ was responsible for manuscript review.

\section{Acknowledgements}

We are incredibly grateful for many helpful comments from anonymous reviewers of an earlier version of this manuscript.

\section{Conflict of interest}

The authors declare that they have no conflict of interest.

\section{References}

[1] Tang X, Wang S, Zhan S et al. The prevalence of symptomatic knee osteoarthritis in china: results from the china health and retirement longitudinal study. Arthritis Rheumatol 2016; 68: 53

[2] Postler A, Ramos AL, Goronzy J, Günther KP, Lange T, Schmitt J, Zink A, Hoffmann F. Prevalence and treatment of hip and knee osteoarthritis in people aged 60 years or older in Germany: an analysis based on health insurance claims data. Clin Interv Aging 2018; 13: 2339-2349

[3] Kucharz E], Szántó S, Ivanova Goycheva M, Petronijević M, Šimnovec K, Domżalski M, Gallelli L, Kamenov Z, Konstantynowicz J, Radunović G, Šteňo B, Stoilov R, Stok R, Vrana R, Bruyère $O$, Cooper C, Reginster JY. Endorsement by Central European experts of the revised ESCEO algorithm for the management of knee osteoarthritis. Rheumatol Int 2019; 39: 1117-1123

[4] Bruyère $\mathrm{O}$, Honvo $\mathrm{G}$, Veronese $\mathrm{N}$ et al. An updated algorithm recommendation for the management of knee osteoarthritis from the European Society for Clinical and Economic Aspects of Osteoporosis, Osteoarthritis and Musculoskeletal Diseases (ESCEO). Seminars in Arthritis and Rheumatism 2019; 49: 337-350

[5] Koh IJ, Kim TK, Chang CB, Cho HJ. In Y. Trends in use of total knee arthroplasty in Korea from 2001 to 2010. Clin Orthop Relat Res 2013; 471: $1441-1450$

[6] Kurtz S, Ong K, Lau E, Mowat F, Halpern M. Projections of primary and revision hip and knee arthroplasty in the United States from 2005 to 2030. J Bone Joint Surg Am 2007; 89: 780-785

[7] Duggal N. Improving orthopedic outcomes: focus on rehabilitation. Orthopedics 2007; 30: 339-341
[8] Youm T, Maurer SG, Stuchin SA. Postoperative management after total hip and knee arthroplasty. J Arthroplasty 2005; 20: 322-324

[9] Harmer AR, Naylor JM, Crosbie J, Russell T. Land-based versus water-based rehabilitation following total knee replacement: a randomized, single-blind trial. Arthritis Rheum 2009; 61: 184-191

[10] Chae CS, Jun JH, Im S, Jang Y, Park GY. Effectiveness of Hydrotherapy on Balance and Paretic Knee Strength in Patients With Stroke: A Systematic Review and Meta-Analysis of Randomized Controlled Trials. Am J Phys Med Rehabil 2020; 99: 409-419

[11] Tidhar D, Drouin J, Shimony A. Aqua lymphatic therapy in managing lower extremity lymphedema. J Support Oncol 2007; 5: 179-183

[12] Mannerkorpi K, Nyberg B, Ahlmen M, Ekdahl C. Pool exercise combined with an education program for patients with fibromyalgia syndrome. A prospective, randomized study. J Rheumatol 2000; 27: 2473-2481

[13] Dong R, Wu Y, Xu S et al. Is aquatic exercise more effective than land-based exercise for knee osteoarthritis? Medicine (Baltimore) 2018; 97: e13823

[14] Erler K, Anders C, Fehlberg G, Neumann U, Brucker L, Scholle HC. Objective assessment of results of special hydrotherapy in inpatient rehabilitation following knee prosthesis implantation [German]. Z Orthop Ihre Grenzgeb 2001; 139: 352-358

[15] Becker BE. Biophysiologic aspects of hydrotherapy. In: Cole AJ, Becker BE editors Comprehensive aquatic therapy. Philadelphia: Butterworth Heinemann; 2004

[16] Sekome K, Maddocks S. The short-term effects of hydrotherapy on pain and self-perceived functional status in individuals living with osteoarthritis of the knee joint. S Afr J Physiother 2019; 75: 476 Published 2019 Jul 24

[17] Moher D, Liberati A, Tetzlaff J, Altman DG. PRISMA Group. Preferred reporting items for systematic reviews and meta-analyses: The PRISMA statement. PLoS Med 2009; 6: e1000097

[18] Higgins JPT, Altman DG, Gøtzsche PC, Jüni P, Moher D, Oxman AD, Savovic J, Schulz KF, Weeks L, Sterne JAC et al. The Cochrane Collaboration's tool for assessing risk of bias in randomised trials. BM] 2011; 343: d5928

[19] Rahmann AE, Brauer SG, Nitz JC. A specific inpatient aquatic physiotherapy program improves strength after total hip or knee replacement surgery: a randomized controlled trial. Arch Phys Med Rehabil 2009; 90: 745-755

[20] Valtonen A, Pöyhönen T, Sipilä S, Heinonen A. Effects of aquatic resistance training on mobility limitation and lower-limb impairments after knee replacement. Arch Phys Med Rehabil 2010; 91: 833-839

[21] Valtonen A, Pöyhönen T, Sipilä S, Heinonen A. Maintenance of aquatic training-induced benefits on mobility and lower-extremity muscles among persons with unilateral knee replacement. Arch Phys Med Rehabil 2011; 92: 1944-1950

[22] Giaquinto S, Ciotola E, Dall'Armi V, Margutti F. Hydrotherapy after total knee arthroplasty. A follow-up study. Arch Gerontol Geriatr 2010; 51: 59-63

[23] Liebs TR, Herzberg W, Rüther W et al. Multicenter randomized controlled trial comparing early versus late aquatic therapy after total hip or knee arthroplasty. Arch Phys Med Rehabil 2012; 93: 192-199. doi:10.1016/j.apmr.2011.09.011

[24] Liebs TR, Herzberg W, Rüther W, Russlies M, Hassenpflug J. Multicenter Arthroplasty Aftercare Project, MAAP. Quality-Adjusted Life Years Gained by Hip and Knee Replacement Surgery and Its Aftercare. Arch Phys Med Rehabil 2016; 97: 691-700. doi:10.1016/j. apmr.2015.12.021

[25] Villalta EM, Peiris CL. Early aquatic physical therapy improves function and does not increase risk of wound-related adverse events for adults after orthopedic surgery: a systematic review and meta-analysis. Arch Phys Med Rehabil 2013; 94: 138-148 
[26] Bartels EM, Juhl CB, Christensen R et al. Aquatic exercise for the treatment of knee and hip osteoarthritis. Cochrane Database Syst Rev 2016; 3: CD005523 Published 2016 Mar 23. doi:10.1002/14651858. CD005523.pub3

[27] Bartholdy C, Juhl C, Christensen R, Lund H, Zhang W, Henriksen M. Therole of muscle strengthening in exercise therapy for knee osteoarthritis: A systematic review and meta-regression analysis of randomized trials. Semin Arthritis Rheum 2017; 47: 9-21

[28] Rewald S, Lenssen AFT, Emans P], de Bie RA, van Breukelen G, Mesters I. Aquatic Cycling Improves Knee Pain and Physical Functioning in Patients With Knee Osteoarthritis: A Randomized Controlled Trial [published online ahead of print, 2020 Mar 10]. Arch Phys Med Rehabil. 2020; S0003-999330147-30147

[29] Ivey FM, Tracy BL, Lemmer JT et al. Effects of strength training and detraining on muscle quality: age and gender comparisons. J Gerontol A Biol Sci Med Sci 2000; 55: B152-7. discussion B158-B159

[30] Taaffe DR, Henwood TR, Nalls MA, Walker DG, Lang TF, Harris TB. Alterations in muscle attenuation following detraining and retraining in resistance-trained older adults. Gerontology 2009; 55: 217-223

[31] Gusi N, Tomas-Carus P, Hakkinen A, Hakkinen K, Ortega-Alonso A. Exercise in waist-high warm water decreases pain and improves health-related quality of life and strength in the lower extremities in women with fibromyalgia. Arthritis Rheum 2006; 55: 66-73
[32] Tomas-Carus P, Hakkinen A, Gusi N, Leal A, Hakkinen K, OrtegaAlonso A. Aquatic training and detraining on fitness and quality of life in fibromyalgia. Med Sci Sports Exerc 2007; 39: 1044-1050

[33] Paxton EW, Torres A, Love RM, Barber TC, Sheth DS, Inacio MCS. Total joint replacement: A multiple risk factor analysis of physical activity level 1-2 years postoperatively. Acta Orthop 2016; 87: 44-49

[34] Ranawat CS, Ranawat AS, Mehta A. Total knee arthroplasty rehabilitation protocol: what makes the difference? J Arthroplasty 200318 (3 Suppl 1): 27-30

[35] Antonelli M, Donelli D. Effects of balneotherapy and spa therapy on levels of cortisol as a stress biomarker: a systematic review. Int J Biometeorol 2018; 62: 913-924. https://doi.org/10.1007/s00484018-1504-8

[36] Antonelli M, Donelli D, Fioravanti A. Effects of balneotherapy and spa therapy on quality of life of patients with knee osteoarthritis: a systematic review and meta-analysis. Rheumatol Int 2018; 38: 1807-1824

[37] Mayr HO, Reinhold M, Bernstein A, Suedkamp NP, Stoehr A. Sports activity following total knee arthroplasty in patients older than 60 years. J Arthroplasty 2015; 30: 46-49

[38] Winther SB, Foss OA, Wik TS, Davis SP, Engdal M, Jessen V, Husby OS. 1-year follow-up of 920 hip and knee arthroplasty patients after implementing fast-track. Acta Orthop 2015; 86: 78-85

\section{Optimale Ernährung im Sport}

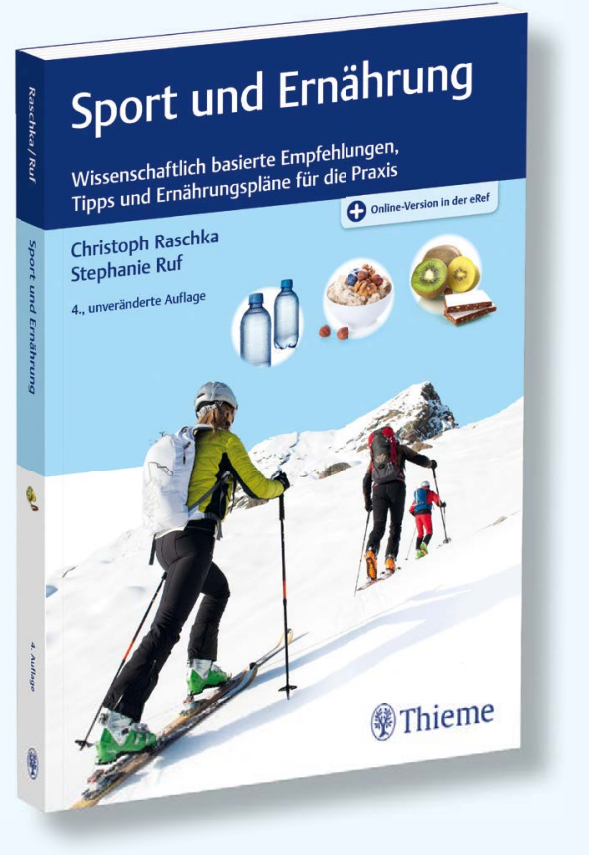

Tipps für die optimale Sportler-Ernährung: wissenschaftlich fundiert und sofort praktisch umsetzbar. Mit diesem Werk gewinnen Sie Kenntnisse über die optimale Energie-, Nährstoff- und Flüssigkeitszufuhr. Lesen Sie über die spezifischen Anforderungen an die Ernährung in Training und Wettkampf.

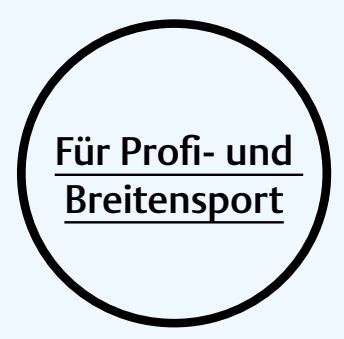

Sport und Ernährung

Raschka/Ruf

2018. 4. Aufl.

232 S., 42 Abb., kart.

ISBN 9783132425910

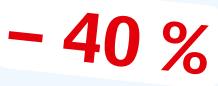

Statt $49,99 €$ jetzt nur $29,99 €[$ [D] 